\title{
Frequency and Characteristics of Responders to an Educational Intervention to Reduce Inappropriate Heart Testing: A Sub-study of the Echo WISELY Trial
}

\section{Frequência e Características dos Respondedores a uma Intervenção Educacional para Redução de Testes Cardíacos Inapropriados: um Subestudo do Echo WISELY Trial}

João Ricardo Pinto Lopes ${ }^{1}$, Cherry Chu², Sacha Bhatia², Luis Claudio Correia ${ }^{1}$

${ }^{1}$ Bahiana School of Medicine and Public Health, Salvador, BA, Brazil; ${ }^{2}$ Women's College Hospital, Toronto, Ontario, Canada.

\begin{abstract}
Introduction: The Echo WISELY Trial is a controlled randomized multicenter investigator-blinded study that evaluated an educational intervention based on the criteria for appropriate use of echocardiography to reduce the proportion of rarely appropriate outpatient echocardiograms performed.
\end{abstract}

Objective: To describe the prevalence and identify predictors of the responsiveness of responding physicians subjected to an educational intervention in the Echo WISELY Trial.

Methods: The intervention group physicians received a multifaceted educational program. A responding physician was defined as one who had a $>2.5 \%$ reduction in the proportional mean of rarely appropriate tests requested between the first trimester (baseline) and any of the following trimesters (second to sixth). Physician characteristics (sex, time since graduation, medical specialty, and workplace) were compared to the echocardiogram ratings (appropriate, maybe appropriate, and rarely appropriate) and clinical reasons for the requested echocardiograms using the chi-square test. Statistical significance was indicated by a two-tailed $\mathrm{p}<0.05$.

Results: A total of 4,605 tests requested at the six participating hospitals in Ontario were analyzed and randomized for the intervention arm. Of the 36 included physicians, 26 (72\%) were classified as responders. Of the variables analyzed, there was no significant difference in the outcomes of the responders versus non-responders to the educational intervention. The number of rarely appropriate tests requested by the responders was significantly lower than that of the non-responders (234 [8.67\%] versus 261 [13.8\%]; $p<0.0001)$.

Conclusion: The prevalence of responder physicians was high, but predictors of responsiveness to educational intervention were not identified among the analyzed variables. This may be a result of the psychological aspects and personal characteristics of the physicians, which were not included in this research.

Keywords: Echocardiography; Prevalence.

\section{Resumo}

Introdução: O Echo WISELY Trial é um estudo controlado, randomizado, multicêntrico, cego pelo investigador, que avaliou uma intervenção educacional com base nos critérios de uso apropriado para ecocardiografia para redução da proporção de ecocardiogramas raramente apropriados realizados ambulatorialmente.

Objetivo: Descrever a prevalência e identificar preditores de responsividade de médicos respondedores submetidos à intervenção educacional no Echo WISELY Trial.

Métodos: Médicos do grupo intervenção receberam um programa educacional multifacetado. O médico respondedor foi definido como aquele que apresentou redução $>2,5 \%$ na média proporcional de exames raramente apropriados solicitados entre o primeiro trimestre (linha de base) e qualquer um dos seguintes trimestres (segundo ao sexto). Foram comparadas as características do médico (sexo, tempo de formação, especialidade médica e local de trabalho) com as classificações dos ecocardiogramas (apropriado, talvez apropriado e raramente apropriado) e razões clínicas para ecocardiogramas solicitados utilizando teste do qui-quadrado. A significância estatística foi indicada por $p$ $<0,05$ bicaudal.

Mailing Address: João Ricardo Pinto Lopes •

Rua Gregório Amâncio, 5, Centro, CEP: 48730-000, Conceição do Coité, BA, Brazil.

E-mail: jrpintolopes@yahoo.com.br

Manuscript received 9/6/2021; revised 9/10/2021; accepted 9/13/2021

DOI: $10.47593 / 2675-312 X / 20213404$ eabc249 
Resultados: Foram analisados 4.605 exames solicitados nos seis hospitais participantes de Ontário e randomizados para o braço intervenção. Dentre os 36 médicos incluídos, 26 (72\%) foram classificados como respondedores. Entre as variáveis analisadas, não houve diferença significativa entre médicos respondedores e não respondedores à intervenção educacional. O número de exames raramente apropriados solicitados pelos respondedores foi significativamente menor que o de não respondedores $(234 ; 8,67 \%$ versus $261 ; 13,8 \% ; \mathrm{p}<0,0001)$.

Conclusão: A prevalência de médicos respondedores é alta, porém não foram identificados preditores de responsividade à intervenção educacional entre as variáveis analisadas. Isso pode decorrer de aspectos psicológicos e características pessoais dos médicos, que não foram incluídos nesta pesquisa.

Palavras-chave: Ecocardiografia; Prevalência.

\section{Introduction}

Echocardiography is an important imaging modality for the diagnosis and treatment of cardiovascular diseases ${ }^{1,2}$, representing approximately half of all cardiac diagnostic tests requested. ${ }^{3}$ However, in many cases, it is used as a screening tool in patients at low risk for cardiovascular disease. ${ }^{4}$ In recent years, there has been a significant increase in the number of echocardiogram requests, estimated at $6-8 \%$ per year. ${ }^{3.5}$ This trend has contributed to progressively increased public spending on medical testing. ${ }^{6}$

Appropriate echocardiography use criteria ${ }^{7}$ were published by the American Society of Echocardiography to reduce unnecessary testing, improve care quality, and optimize cost-effectiveness. Appropriate use criteria for echocardiography are clinical scenarios classified as "appropriate," "maybe appropriate," or "rarely appropriate" based on clinical indications. A test can be classified as rarely appropriate if the indication is not an approved reason for testing or if the test is unlikely to benefit the patient. Many efforts have been made to address this issue - most notably, the development of the Choosing WISELY international campaign, which strives to raise awareness of and prevent the overuse of health services. ${ }^{8}$

The Echo WISELY (Will Inappropriate Scenarios for Echocardiography Lessen SignificantlY in an education RCT) Trial evaluated an educational intervention based on the appropriate use criteria for echocardiography and its ability to reduce the proportion of rarely appropriate transthoracic echocardiograms requested by clinicians in outpatient care. The results demonstrated that the physicians who completed the intervention over 18 months requested a significantly lower proportion of rarely appropriate tests than those randomized to the control arm. ${ }^{9}$ However, there was still notable variation in the proportion of rarely appropriate tests requested by the physicians who received the intervention. This exploratory substudy of the Echo WISELY Trial had two objectives: describe the prevalence of physicians responding to an educational intervention in the Echo WISELY Trial and identify predictors of responsiveness.

\section{Methods}

\section{Study design and participants}

The trial protocol was previously published. ${ }^{10}$ The Echo WISELY Trial, which was multicenter, randomized, controlled, and investigator-blinded, demonstrated the effectiveness of an educational intervention to reduce the proportion of rarely appropriate outpatient transthoracic echocardiograms requested by primary care physicians and cardiologists in the intervention arm. The intervention involved education and feedback and was based on appropriate use criteria for echocardiography. ${ }^{7}$ Between December 2014 and April 2016, 75 cardiologists and primary care physicians were recruited from eight hospitals in Ontario, Canada, and Massachusetts, United States. Physicians were randomized 1:1 to receive the intervention versus the usual care. The study was registered at ClinicalTrials.gov (NCT02038101), reported in accordance with the Consolidated Standards of Reposting Trails (CONSORT) guidelines, and approved by the ethics committees of the participating hospitals.

The sub-study was descriptive and included only Ontario physicians from the intervention arm of the study to explore the response phenomenon. Physicians without a College of Physicians and Surgeons of Ontario (CPSO) registration number were excluded from the analysis to ensure that each physician could be linked to their baseline characteristics.

\section{Intervention}

Physicians assigned to the intervention group received a multifaceted educational approach that included a 20-minute informational video describing the appropriate use criteria and key scenarios in which echocardiogram tests should be requested; detailed instructions on how to access the educational application on appropriate use criteria for echocardiography; and individual monthly reports detailing the test request pattern of each physician versus their peers, including the total number of appropriate, maybe appropriate, and rarely appropriate tests ordered.

\section{Echocardiogram appropriate use classification}

The echocardiograms requested by the participating physicians during the study period were evaluated for adequacy according to the appropriate use criteria for echocardiography published in 2011. ${ }^{7}$ The evaluators were not aware of the treatment allocations. For each requested echocardiogram, the clinical reasons for the request and the patient's chart (including disease history, treatment plans, and previous requests for medical imaging tests) were recorded. Each test was rated as appropriate, maybe appropriate, or rarely appropriate. Tests with insufficient clinical data for the judgment of appropriate use were not included in the study. For tests lacking clear classification information, the principal site investigator was first asked to 
rate their appropriateness. If a decision could not be made, the test was then evaluated by a committee composed of three senior study researchers.

\section{Classification of responding physicians}

The quarterly frequency of the requested echocardiograms was plotted for all physicians who requested at least one echocardiogram in each quarter. Responders were defined as physicians who demonstrated a reduced number of rarely appropriate echocardiograms between baseline and the final period of more than the mean difference between the intervention and control groups. This mean effect of the intervention was a $2.5 \%$ reduction. ${ }^{9}$ In addition, a physician was considered a responder if no rarely appropriate tests were requested in any of the follow-up quarters.

\section{Statistical analysis}

The intervention period lasted 18 months and was divided into six quarters for the analysis. For each individual physician, the proportions of rarely appropriate tests requested during each of the following quarters (second through sixth) were subtracted from the proportion in the first quarter (baseline). The mean of these deltas for each physician was defined as the mean reduction. The proportion of those with a delta reduction of at least $>2.5 \%$, defined as responders, was described and the 95\% confidence interval $(\mathrm{Cl})$ was calculated. Distributions of several basic medical characteristics between responders and non-responders (sex, years since graduation from medical school, medical specialty, and workplace) were compared, as were classifications based on the appropriate use criteria for echocardiography (appropriate, maybe appropriate, and rarely appropriate) and clinical reasons for requesting echocardiograms using chi-square tests of independence or Fisher's exact tests for cells, with a frequency of $<5$. Statistical significance was indicated by a two-tailed $p<0.05$. All statistical analyses were performed using SPSS version 17 software.

\section{Results}

Of the 14,697 total echocardiograms requested by all physicians participating in the Echo WISELY Trial, 4,605 were analyzed in this sub-study and requested by clinicians randomized to the intervention arm of the six participating hospitals in Ontario. Of the initial sample of 38 physicians, two were excluded: one for lacking a CPSO registration number and the other for not having requested any tests during the entire study period. Of the 36 physicians included in the analysis, 26 (72\%; 95\% Cl, 55-86\%) were classified as responders to the intervention based on the $2.5 \%$ reduction threshold.

During the study, the proportion of rarely appropriate tests requested by the responders was significantly lower than that by the non-responders (234 [8.6\%] versus 261 [13.8\%]; $p<$ $0.0001)$. There was also a difference in the main reasons for requesting rarely appropriate tests between the responders and non-responders $(p<0.0001)$. The main reason for requests among the respondents was number 11 , routine surveillance of ventricular function with known coronary artery disease (CAD) and no change in clinical status or cardiac examination findings (50 [21.4\%]). Of non-responders, the main reason for requesting tests was number 48 , routine surveillance $(<3$ years after implantation) of the prosthetic valve without any known or suspected valvular dysfunction (82 [31.4\%]). Table 1 shows the clinical adequacy and reasons for physician-requested echocardiograms in the responder and non-responder groups.

\section{Responder predictors}

Table 2 compares the baseline physician characteristics between the responders and non-responders. The main characteristics of the responders were: 22 (84\%) were male, 20 (76.9\%) specialized in internal medicine, 24 (92.3\%) specialized in cardiology, 19 (73\%) graduated 21-40 years prior, and 18 (69.3\%) of the responders worked at the Queen's University, St. Michael's Hospital, or the University Health Network. Among the

Table 1 - Characteristics of echocardiogram tests requested by intervention group physicians.

\begin{tabular}{|c|c|c|c|c|c|}
\hline Echocardiogram & $\begin{array}{c}\text { Responders } \\
(n=2,713[59 \%])\end{array}$ & $\begin{array}{c}95 \% \mathrm{Cl} \\
(55-60 \%)\end{array}$ & $\begin{array}{l}\text { Non-responders } \\
(\mathrm{n}=1,892[41 \%])\end{array}$ & $\begin{array}{c}95 \% \mathrm{Cl} \\
(40-43 \%)\end{array}$ & $P$ value \\
\hline Adequacy & & & & & $<0.001$ \\
\hline Appropriate & $2335(86.1)$ & $85-87$ & $1512(79.9)$ & $78-81.7$ & \\
\hline Maybe appropriate & $144(5.3)$ & $4.5-6.2$ & $119(6.3)$ & $5.3-7.5$ & \\
\hline Rarely appropriate & $234(8.6)$ & $7.6-9.7$ & $261(13.8)$ & $12-15.4$ & \\
\hline Reasons for inappropriate requests & & & & & $<0.001$ \\
\hline $\begin{array}{l}\text { 11. Routine surveillance for ventricular function with known CAD; no } \\
\text { change in clinical status or cardiac examination }\end{array}$ & $50(21.4)$ & $16.5-27$ & $52(19.9)$ & 15.3-25 & \\
\hline $\begin{array}{l}\text { 38. Routine surveillance ( }<3 \text { years) for mild valve stenosis; change in } \\
\text { clinical status or cardiac examination findings }\end{array}$ & $16(6.8)$ & $4-10.9$ & $17(6.1)$ & $3.8-10$ & \\
\hline $\begin{array}{l}\text { 40. Routine surveillance (<1 year) for moderate or severe valve } \\
\text { stenosis; no change in clinical status or cardiac examination findings }\end{array}$ & $23(9.8)$ & $6.5-14$ & $45(17.2)$ & $13-22.4$ & \\
\hline $\begin{array}{l}\text { 43. Routine surveillance }(<3 \text { years) for mild valve regurgitation; no } \\
\text { change in clinical status or cardiac examination findings }\end{array}$ & $14(6)$ & $3.5-9.6$ & $16(6.1)$ & $3.5-9.8$ & \\
\hline $\begin{array}{l}\text { 48. Routine surveillance (<3 years after implantation) for prosthetic } \\
\text { valve; no known or suspected valvular dysfunction }\end{array}$ & $24(10.3)$ & $6.8-15$ & $82(31.4)$ & $26-37.4$ & \\
\hline $\begin{array}{l}\text { 88. Routine surveillance (< } 1 \text { year) for known cardiomyopathy; no } \\
\text { change in clinical status or cardiac examination findings }\end{array}$ & $27(11.5)$ & $8-16.1$ & $20(7.7)$ & $4.7-11$ & \\
\hline
\end{tabular}

Results are expressed as n (\%) unless otherwise indicated. 95\% Cl: 95\% confidence interval; CAD: coronary artery disease. 
Table 2 - Characteristics of the intervention group physicians.

\begin{tabular}{|c|c|c|c|c|c|}
\hline Physicians & Responders ( $n=26[72 \%]$ ) & $95 \% \mathrm{Cl}(55-86)$ & Responders (n = $10[28 \%]$ ) & $95 \% \mathrm{Cl}(14-45)$ & $P$ value \\
\hline Male sex & $22(84.0)$ & $65-96$ & $9(90.0)$ & $56-99$ & 0.68 \\
\hline Time since graduation, years & & & & & 0.142 \\
\hline \multicolumn{6}{|l|}{$0-10$} \\
\hline $11-20$ & $2(7.7)$ & $1-25$ & $4(40.0)$ & $12-74$ & \\
\hline $21-30$ & $10(38.5)$ & $20-59$ & $3(30.0)$ & $6.7-65$ & \\
\hline $31-40$ & $9(34.5)$ & $17-56$ & $1(10.0)$ & $0.3-45$ & \\
\hline $41-50$ & $4(15.4)$ & $4-35$ & $1(10.0)$ & $0.3-45$ & \\
\hline $51-60$ & $1(3.8)$ & $0.1-20$ & $1(10.0)$ & $0.3-45$ & \\
\hline \multicolumn{6}{|l|}{ Specialty } \\
\hline Internal medicine & $20(76.9)$ & $56-91$ & $9(90.0)$ & $56-99$ & 0.37 \\
\hline Cardiology & $24(92.3)$ & $75-99$ & $10(100.0)$ & $69-100$ & 0.37 \\
\hline Hospital & & & & & 0.41 \\
\hline Mount Sinai Hospital & $3(11.5)$ & $2.5-30$ & $1(10.0)$ & $0.3-45$ & \\
\hline Queen's University & $6(23.1)$ & $9-43$ & & & \\
\hline St. Michael's Hospital & $6(23.1)$ & $9-43$ & $5(50.0)$ & $18.7-81$ & \\
\hline Sunnybrook Health Sciences Cen & $3(11.5)$ & $2.5-30$ & $2(20.0)$ & $2.5-56$ & \\
\hline University Health Network & $6(23.1)$ & $9-43$ & $1(10.0)$ & $0.3-45$ & \\
\hline Women's College Hospital & $2(7.77)$ & $1-25$ & $1(10.0)$ & $0.3-45$ & \\
\hline
\end{tabular}

Results are expressed as $n(\%)$ unless otherwise indicated. 95\% Cl: 95\% confidence interval.

non-responders, nine $(90 \%)$ were male, nine $(90 \%)$ specialized in internal medicine, 10 (100\%) specialized in cardiology, seven (70\%) graduated $21-40$ years prior. Half of the non-responders worked at St. Michael's Hospital. There were no statistically significant intergroup differences in any of the analyzed variables.

\section{Discussion}

To the best of our knowledge, the Echo WISELY Trial is the first multicenter randomized controlled trial of an educational intervention that aimed to reduce the prevalence of rarely appropriate transthoracic echocardiograms requested by outpatient clinicians. Our results demonstrated a significantly decreased number of rarely appropriate tests requested by intervention group physicians versus control group physicians. The results of this sub-study corroborate that the intervention is effective, as the proportion of physicians who responded to the intervention was high. Thus, educational intervention may be a viable strategy to reduce the potential use of low-value echocardiography and increase adherence to best medical practices.

There was wide variation in the quarterly frequency of rarely appropriate echocardiograms requested by physicians in the Echo WISELY Trial intervention group. However, it was not possible to predict participant responsiveness to the educational intervention using the basic physician characteristics that were studied. This suggests that other aspects may be involved, such as personal characteristics, such as personality or behavioral traits intrinsic to physicians themselves that favor reflection before requesting tests or making decisions. Future research may test this hypothesis using personality assessment instruments.

This sub-study presented a significant difference of $5.2 \%(13.8 \%$ versus $8.6 \%)$ in the proportion of rarely appropriate tests ordered between non-responders and responders in the intervention group. This value is twice the difference in the proportion of rarely appropriate tests found between the intervention and control groups in the original Echo WISELY Trial. There was also a significant difference in the reasons cited by responders versus non-responders for requesting echocardiography. Among the responders, the most frequent reason was routine surveillance of ventricular function with known CAD and no change in clinical status or cardiac examination findings, while in the non-responders group, the main reason was routine surveillance $<3$ years after prosthetic valve implantation without known or suspected valvular dysfunction. Considering that inadequate care can lead to unwanted patient consequences and unnecessary health system expenses, efforts should be made to reduce the number of rarely appropriate echocardiographic tests through guidelines and interventions directed to physicians such as the provision of educational interventions or programs, ${ }^{11-13}$ publication and continuous updating of appropriate use criteria, and implementation of authorized protocols or auditing in laboratories to assess the adequacy of echocardiogram requests. ${ }^{14}$

Initiatives such as Choosing Wisely ${ }^{8}$ were established to raise physician and patient awareness of the issue related to inappropriate use. Some studies identified several factors that can also contribute to the inappropriate use of tests in cardiology, such as cultural, clinical, financial or legal reasons. ${ }^{15,16}$ Educational audit and feedback interventions based on the criteria of appropriate use of echocardiography investigated in previous studies showed benefits of reducing the number of tests that are rarely appropriate or otherwise have low value. However, the maintenance of the longterm effectiveness of these interventions requires ongoing investments in planning as well as training physicians and others involved in the decision-making process. 


\section{CONCLUSION}

A high proportion of physicians were considered responders to the educational intervention, and the prevalence of rarely appropriate tests was significantly different between responders and non-responders. However, no predictive characteristics were identified to differentiate a responder from a non-responder. Psychological and behavioral aspects of the physicians, which were not considered in this study, may be more important predictors of a positive response to educational interventions; thus, future research including behavioral variables may be warranted. A greater understanding of the factors that motivate a physician to respond to the audit and feedback intervention is important to the

\section{References}

1. Cheitlin MD, Alpert JS, Armstrong WF, Aurigemma GP, Beller GA, Bierman FZ, et al. ACC/AHA guidelines for the clinical application of echocardiography: executive summary. A report of the American College of Cardiology/American Heart Association Task Force on practice guidelines (Committee on Clinical Application of Echocardiography). Developed in collaboration with the American Society of Echocardiography. J Am Coll Cardiol. 1997;29(4):862-79. doi: 10.1016/s0735-1097(96)90000-5

2. Ducci C, Edvardsen T, Kitsiou A, Nieman K, Lancellotti P; EACVI Imaging Task Force. Appropriateness criteria for cardiovascular imaging use in heart failure: report of literature review. Eur Heart J Cardiovasc Imaging. 2015;16(2):147-53. doi: 10.1093/ehjci/jeu299

3. Pearlman AS, Ryan T, Picard MH, Douglas PS. Evolving trends in the use of echocardiography: a study of Medicare beneficiaries. J Am Coll Cardiol. 2007;49(23):2283-91. doi: 10.1016/j.jacc.2007.02.048

4. Colla CH, Sequist TD, Rosenthal MB, Schpero WL, Gottlieb DJ, Morden NE. Use of non-indicated cardiac testing in low-risk patients: choosing wisely. BMJ Qual Saf. 2015;24(2):149-53. doi: 10.1136/bmjqs-2014-003087

5. Blecker S, Bhatia RS, You JJ, Lee DS, Alter DA, Wang JT, et al. Temporal trends in the utilization of echocardiography in Ontario, 2001 to 2009. JACC Cardiovasc Imaging. 2013;6(4):515-22. doi: 10.1016/j.jcmg.2012.10.026

6. Douglas PS. Quality in echocardiography: choosing to succeed. J Am Soc Echocardiogr. 2008;21(9):1016-7. doi: 10.1016/j.echo.2008.07.010

7. American College of Cardiology Foundation Appropriate Use Criteria Task Force; American Society of Echocardiography; American Heart Association; American Society of Nuclear Cardiology; Heart Failure Society of America; Heart Rhythm Society; Society for Cardiovascular Angiography and Interventions; Society of Critical Care Medicine; Society of Cardiovascular Computed Tomography; Society for Cardiovascular Magnetic Resonance; American College of Chest Physicians, Douglas PS, Garcia MJ, Haines DE, Lai WW, Manning WJ, Patel AR, et al. ACCF/ASE/AHA/ASNC/HFSA/HRS/SCAl/ SCCM/SCCT/SCMR 2011 Appropriate Use Criteria for Echocardiography. A Report of the American College of Cardiology Foundation Appropriate Use Criteria Task Force, American Society of Echocardiography, American Heart Association, American Society of Nuclear Cardiology, Heart Failure Society of America, Heart Rhythm Society, Society for Cardiovascular Angiography and Interventions, Society of Critical Care Medicine, Society of adaptation of future medical interventions and maximize their effectiveness against inappropriate use.

\section{Authors' contributions}

Study conception: JRP Lopes, LC Correia, C Chu, and S Bhatia; research design: JRP Lopes, LC Correia, C Chu, and S Bhatia; data collection: JRP Lopes, C Chu, and S Bhatia; data analysis and interpretation: JRP Lopes, LC Correia, C Chu, and S Bhatia; statistical analysis: JRP Lopes, C Chu, and S Bhatia; manuscript writing: JRP Lopes, LC Correia, and C Chu.

\section{Conflict of interest}

The authors have declared that they have no conflict of interest.

Cardiovascular Computed Tomography, Society for Cardiovascular Magnetic Resonance American College of Chest Physicians. J Am Soc Echocardiogr. 2011;24(3):229-67. doi: 10.1016/j.echo.2010.12.008

8. Born KB, Levinson W. Choosing Wisely campaigns globally: A shared approach to tackling the problem of overuse in healthcare. J Gen Fam Med. 2018;20(1):9-12. doi: 10.1002/jgf2.225

9. Bhatia RS, Ivers NM, Yin XC, Myers D, Nesbitt GC, Edwards J, et al. Improving the Appropriate Use of Transthoracic Echocardiography: The Echo WISELY Trial. J Am Coll Cardiol. 2017;70(9):1135-44.

10. Bhatia RS, Ivers N, Yin CX, Myers D, Nesbitt G, Edwards J, et al. Design and methods of the Echo WISELY (Will Inappropriate Scenarios for Echocardiography Lessen SignificantlY) study: An investigator-blinded randomized controlled trial of education and feedback intervention to reduce inappropriate echocardiograms. Am Heart J. 2015;170(2):202-9. doi: 10.1016/j.ahj.2015.04.022

11. Bhatia RS, Dudzinski DM, Malhotra R, Milford CE, Yoerger Sanborn $\mathrm{DM}$, Picard $\mathrm{MH}$, et al. Educational intervention to reduce outpatient inappropriate echocardiograms: a randomized control trial. JACC Cardiovasc Imaging. 2014;7(9):857-66. doi: 10.1016/j.jcmg.2014.04.014

12. Bhatia RS, Dudzinski DM, Milford CE, Picard MH, Weiner RB. Educational intervention to reduce inappropriate transthoracic echocardiograms: the need for sustained intervention. Echocardiography. 2014;31(8):916-23. doi: 10.1111/echo.12505

13. Bhatia RS, Milford CE, Picard MH, Weiner RB. An educational intervention reduces the rate of inappropriate echocardiograms on an inpatient medical service. JACC Cardiovasc Imaging. 2013;6(5):545-55. doi: 10.1016/j. jcmg.2013.01.010

14. Fonseca R, Marwick TH. How I do it: judging appropriateness for TTE and TEE. Cardiovasc Ultrasound. 2014;12:22. doi: 10.1186/1476-7120-12-22

15. Huang X, Rosenthal MB. Overuse of Cardiovascular Services: Evidence Causes, and Opportunities for Reform. Circulation. 2015;132(3):205-14. doi: 10.1161/CIRCULATIONAHA.114.012668

16. Carroll AE. The High Costs of Unnecessary Care. JAMA. 2017;318(18):1748 9. doi: 10.1001/jama.2017.16193. 